Check for updates

Cite this: RSC Adv., 2019, 9, 18641

\title{
Synthesis of a novel magnetic Caragana korshinskii biochar/Mg-Al layered double hydroxide composite and its strong adsorption of phosphate in aqueous solutions $\dagger$
}

\author{
Qingliang Cui, ${ }^{\text {ac }}$ Gaojie Jiao, ${ }^{\text {ac }}$ Jiyong Zheng, (D) *ab Tongtong Wang, (D) ab Gaolin Wu ${ }^{\text {ab }}$ \\ and Gaoliang Lic
}

Phosphate pollution of aquatic ecosystems is of great concern and requires the development of highperformance materials for effective pollution treatment. To realize efficient phosphate removal from aqueous solution, an easily separable magnetic $\left(\mathrm{Fe}_{3} \mathrm{O}_{4}\right)$ Caragana korshinskii biochar/Mg-Al layered double hydroxide composite (denoted as $\mathrm{FCB} / \mathrm{MAC}$ ) was synthesized via two-step electro-assisted modification for the first time. Subsequently, the physical and chemical properties of FCB/MAC were characterized. Furthermore, the sorption mechanism for phosphate removal was investigated in detail. The results indicated that $\mathrm{Fe}_{3} \mathrm{O}_{4}$ and the $\mathrm{Mg}$-Al layered double hydroxide were successfully embedded in the biochar matrix. Moreover, FCB/MAC exhibited a high phosphate adsorption capacity and excellent magnetic properties for easy recovery. The maximum phosphate sorption capacity of FCB/MAC was $252.88 \mathrm{mg} \mathrm{g}^{-1}$, which is much higher than the capacities of most magnetic phosphate adsorbents. In addition, the adsorption kinetics and isotherms indicated that phosphate adsorption by FCB/MAC was controlled by the pseudo-second-order kinetic model and the Langmuir-Freundlich isotherm model. The phosphate adsorption mechanism involves anion exchange, electrostatic attraction, and ligand exchange. After five adsorption-desorption cycles, the phosphate adsorption capacity of FCB/MAC was $25.71 \mathrm{mg} \mathrm{g}^{-1}$ with $51.43 \%$ removal efficiency and high recyclability. Thus, the composite prepared in this study is a promising adsorbent for phosphate removal from aqueous solution, and this work provides an excellent reference for constructing novel biochar-based phosphate adsorbents.

\author{
Received 17th March 2019 \\ Accepted 5th June 2019 \\ DOI: $10.1039 / \mathrm{c} 9 \mathrm{ra02052g}$ \\ rsc.li/rsc-advances
}

\section{Introduction}

Phosphate, as a basic nutrient, is vital for the growth of aquatic organisms. However, the excessive emission of phosphate into runoff systems has been confirmed to cause eutrophication, which can result in serious water quality deterioration and aquatic ecosystem collapse. Furthermore, phosphate pollution not only could increase the cost of water treatment and decrease the recreational value of waterways but also lead to the formation of algal blooms, which is harmful to human health owing to the production of cyanotoxins. ${ }^{1}$ Therefore, there is an

${ }^{a}$ State Key Laboratory of Soil Erosion and Dryland Farming on Loess Plateau, Institute of Soil and Water Conservation, Chinese Academy of Sciences and Ministry of Water Resources, Yangling, Shaanxi, 712100, China. E-mail: zhjy@ms.iswc.ac.cn; Fax: +86-29-87016082; Tel: +86-29-87012884

${ }^{b}$ State Key Laboratory of Soil Erosion and Dryland Farming on Loess Plateau, Northwest A\&F University, Yangling, Shaanxi 712100, China 'University of Chinese Academy of Sciences, Beijing 100049, China

$\uparrow$ Electronic supplementary information (ESI) available. See DOI: 10.1039/c9ra02052g immediate need to remove excess phosphates from aquatic ecosystems.

Biochar, a pyrogenic black carbon, is mainly produced from various carbon-rich biomass and waste sources by thermal decomposition processes under moderate temperatures and oxygen-limited environments. ${ }^{2}$ Owing to its wide environmental applications and excellent physicochemical properties, such as high surface porosity and numerous surface functional groups, biochar has been recognized as an promising adsorbent for the removal of various contaminants in solution. ${ }^{3}$ However, the net negative surface charge of biochar seriously limits its adsorption affinity towards anions such as phosphate. ${ }^{\mathbf{4} 5}$ For example, the phosphate adsorption capacities of biochar from corn cobs, garden wood waste, and wood chips are $0.036,0.132$, and $0.296 \mathrm{mg}$ $\mathrm{g}^{-1}$, respectively. ${ }^{6}$ In addition, difficulties in separating and recycling biochar from phosphate solutions have seriously restricted its application in wastewater remediation. Therefore, methods for simultaneously improving the phosphate adsorption capacity and recovery efficiency of biochar are essential. 
With the aim of improving the phosphate adsorption capacity and recycling performance of biochar, some composites, such as $\mathrm{MgFe}_{2} \mathrm{O}_{4^{-}}$and $\mathrm{La} / \mathrm{Fe}_{3} \mathrm{O}_{4}$-modified biochar composites, have been produced by grafting iron and another metal onto biochar. ${ }^{7-11}$ However, the phosphate adsorption capacities of these metal-modified biochar composites were still low. However, the formation of magnetic layered double hydroxides (LDHs) on the surface of biochar can greatly improve the adsorption capacity because LDHs are cationic clays with large anion sorption capacities. LDHs consist of positively charged metal hydroxide layers and are generally described as $\left[\mathrm{M}_{1-x}{ }^{2+} \mathrm{M}_{x}{ }^{3+}(\mathrm{OH})_{2}\right]\left[\mathrm{A}^{n-}\right]_{x / n} \cdot y \mathrm{H}_{2} \mathrm{O}$, where $\mathrm{M}^{2+}$ is a divalent cation $\left(\mathrm{Mg}^{2+}, \mathrm{Cu}^{2+}, \mathrm{Zn}^{2+}\right.$, etc. $), \mathrm{M}^{3+}$ is a trivalent cation $\left(\mathrm{Fe}^{3+}, \mathrm{Al}^{3+}, \mathrm{Cr}^{3+}\right.$, etc. $)$, and $\mathrm{A}^{n-}$ is an interlayer anion $\left(\mathrm{CO}_{3}{ }^{2-}\right.$, $\mathrm{NO}_{3}{ }^{-}, \mathrm{Cl}^{-}, \mathrm{OH}^{-}$, etc. $)$. In general, the $x$ value ranges between 0.17 and $0.33 .^{12} \mathrm{LDH}$ composites have exhibited excellent abilities to adsorb pollutants. ${ }^{\mathbf{1 3 - 1 7}}$ However, LDHs may have limited capabilities for removing anion contaminants owing to their tight layer stacking. Therefore, composite materials were prepared by introducing biochar onto the LDH frame, which can increase efficiency and reduce costs.

The methods for modifying biochar include microwave irradiation, ${ }^{18}$ hydrothermal coprecipitation, ${ }^{\mathbf{1 9}, 20}$ and electroassisted modification. ${ }^{21}$ However, microwave irradiation is complex, and hydrothermal coprecipitation is time consuming when more than two chemicals are utilized. Furthermore, the general electro-assisted modification method gives products that are unstable. However, the electro-assisted modification method could provide some advantages, as it is simple to operate, rapid, and allows upgrading of the properties of modified biochar via the generation of crystalline structures. Therefore, there is an urgent need for an improved electroassisted modification method.

In this study, the general electro-assisted modification method was optimized to facilitate both obtaining a biochar with magnetic properties and producing an LDH on the biochar surface. A novel strategy of fabricating magnetite $\left(\mathrm{Fe}_{3} \mathrm{O}_{4}\right)$ and a $\mathrm{Mg}-\mathrm{Al} \mathrm{LDH}$ via a two-step electro-assisted modification process was developed. Magnetic $\mathrm{Fe}_{3} \mathrm{O}_{4}$ and the $\mathrm{Mg}-\mathrm{Al} \mathrm{LDH}$ were introduced to Caragana korshinskii biochar during the synthesis process to obtain a magnetic $\left(\mathrm{Fe}_{3} \mathrm{O}_{4}\right)$ C. korshinskii biochar/Mg-Al LDH composite (denoted as FCB/MAC). The surface morphology, chemical composition, and magnetic properties of FCB/MAC were characterized. In addition, a series of batch experiments were carried out to investigate the effects of various parameters (initial $\mathrm{pH}$, coexisting anions, contact time, and initial phosphate concentration) on the phosphate adsorption performance of FCB/MAC and elucidate the phosphate adsorption mechanism. Furthermore, the phosphate desorption behavior and recyclability of phosphate-loaded FCB/ MAC were also evaluated.

\section{Materials and methods}

\subsection{Materials}

As a biochar precursor, C. korshinskii was collected from Shanghuang Village, Guyuan City, Ningxia Hui Autonomous
Region, China. Owing to the low utilization rate of $C$. korshinskii $(<40 \%)$, there is a high abundance of most C. korshinskii resources. All chemicals were of AR grade and were purchased from Sinopharm Chemical Reagent Co., Ltd. (China). All experimental solutions were prepared using deionized (DI) water. Iron and aluminum electrodes were purchased from Goodfellow Cambridge Ltd. (UK).

\subsection{Adsorbent preparation}

2.2.1. Biochar production. The $C$. korshinskii raw materials were washed and dried in a vacuum oven for $24 \mathrm{~h}$. Then, the dry raw materials were cut into pieces smaller than $2 \mathrm{~mm}$. The $C$. korshinskii pieces were pyrolyzed in a box-type atmosphere furnace (GF11Q-8, Nanjing Boyuntong Instrument Technology Co., Ltd., China) at $600{ }^{\circ} \mathrm{C}$ for $2 \mathrm{~h}$ with a heating rate of $10{ }^{\circ} \mathrm{C} \min ^{-1}$ under a constant $\mathrm{N}_{2}$ flow. A three-stage temperature-programmed thermal cracking method was used, with a uniform heating time of $1 \mathrm{~h}$ and a cooling time of $1 \mathrm{~h}$. After the sample was cooled to room temperature, the biochar material was broken into powder using an agate mortar and pestle, and then sieved to a particle size of less than $0.1 \mathrm{~mm}$.

2.2.2. Synthesis of $\mathrm{Fe}_{3} \mathrm{O}_{4}$ magnetic biochar. Magnetic $C$. korshinskii biochar was prepared using an electro-assisted modification procedure similar to a previously reported method..$^{21}$ In brief, $3.0 \mathrm{~g}$ of biochar was dipped in $500 \mathrm{~mL}$ of a $\mathrm{NaCl}$ electrolyte $\left(1.0 \mathrm{~g} \mathrm{~L}^{-1}\right)$. For electro-assisted modification of the biochar, a current density $\left(123.91 \mathrm{~mA} \mathrm{~cm}^{-2}\right)$ was applied for 5 min using a power supply (FTS12-100 Programmable DC Power Supply, Faithtech Co., China) and iron electrodes (each electrode had dimensions of $\Phi 10 \times 150 \mathrm{~mm}$ ), which were placed perpendicularly in the electrolyte. The effective surface area and distance of each electrode were $32.20 \mathrm{~cm}^{2}$ and $6 \mathrm{~cm}$, respectively. After the electro-assisted modification process, the precipitates were collected using a magnet, washed with DI water three times, and finally dried at $60{ }^{\circ} \mathrm{C}$ under a $\mathrm{N}_{2}$ environment.

2.2.3. Synthesis of $\mathbf{F C B} / \mathbf{M A C}$. First, $3.0 \mathrm{~g}$ of $\mathrm{Fe}_{3} \mathrm{O}_{4}$ magnetic biochar was dipped in $500 \mathrm{~mL}$ of a $\mathrm{MgCl}_{2}$ electrolyte $\left(5.0 \mathrm{~g} \mathrm{~L}^{-1}\right)$. A current density $\left(123.91 \mathrm{~mA} \mathrm{~cm}^{-2}\right)$ was applied for $5 \mathrm{~min}$ using a power supply and aluminum electrodes. The obtained compound was aged for $24 \mathrm{~h}$ at $80{ }^{\circ} \mathrm{C}$ and the solution $\mathrm{pH}$ was adjusted to 9.0 with $0.5 \mathrm{M}$ solutions of $\mathrm{H}_{2} \mathrm{SO}_{4}$ and $\mathrm{NaOH}$. Then, the precipitates were collected through centrifugation, washed with DI water, and oven-dried at $60{ }^{\circ} \mathrm{C}$ under a $\mathrm{N}_{2}$ environment.

\subsection{Characterization}

To investigate the surface morphology and structure of the modified biochar, scanning electron microscopy (FE-SEM, JEOL 7800F, Japan) was employed. Furthermore, the element contents were characterized by energy-dispersive X-ray spectroscopy (EDS). X-ray diffraction (XRD) analysis was performed to identify any crystalline structures in the biochar samples using a computer-controlled X-ray diffractometer (XRD-6100, Shimadzu, Japan). The BET surface area and total pore volume of the biochar samples were obtained using $\mathrm{N}_{2}$ sorption on an ASAP 2020 Plus HD88 instrument (Micromeritics Inc., 
USA). The surface elemental composition was examined by $\mathrm{X}$ ray photoelectron spectroscopy (XPS, ESCALab Xi+, Thermo Scientific, USA). The magnetization curve of the product was measured using a MPMS-SQUID-094 vibrating sample magnetometer (VSM, Quantum Design, USA) with an applied field between -10000 and $10000 \mathrm{Oe}$ at $298 \mathrm{~K}$. Fourier transform infrared (FT-IR) spectra were recorded in the range of 4000$400 \mathrm{~cm}^{-1}$ using a FT-IR spectrometer (Nicolet iS50, Thermo Scientific, USA). Inductively coupled plasma mass spectrometry (ICP-MS, NexlON 350D, PerkinElmer, USA) was used to detect the leaching concentrations of $\mathrm{Fe}, \mathrm{Mg}$, and $\mathrm{Al}$ from the adsorbent. The zeta potential was analyzed using a zeta potential analyzer (Zetasizer Nano ZSE, Malvin, UK).

\subsection{Phosphate adsorption experiments}

Adsorption experiments were performed to determine the phosphate adsorption capacity of FCB/MAC. Specifically, a stock solution of $500 \mathrm{mg}_{\mathrm{P}} \mathrm{L}^{-1}$ was prepared by dissolving $2.195 \mathrm{~g}$ of $\mathrm{KH}_{2} \mathrm{PO}_{4}$ in $1.0 \mathrm{~L}$ DI water. Then, the stock solution was diluted to prepare phosphate solutions with various phosphate concentrations. First, the effect of $\mathrm{pH}$ on phosphate adsorption was investigated in the $\mathrm{pH}$ range 3.0-11.0 with an interval of 1.0. The $\mathrm{pH}$ values of the solutions were adjusted by adding $0.1 \mathrm{M}$ $\mathrm{HCl}$ or $\mathrm{NaOH}$. Then, $0.05 \mathrm{~g}$ of adsorbent was added to $50 \mathrm{~mL}$ of each phosphate solution $\left(50 \mathrm{mg}_{\mathrm{P}} \mathrm{L}^{-1}\right)$, and the reaction vessels were agitated using a shaker operating at $120 \mathrm{rpm}$ at a constant temperature of $25 \pm 1{ }^{\circ} \mathrm{C}$ for $12 \mathrm{~h}$. The samples were immediately filtered using a syringe filter $(0.45 \mu \mathrm{m}$ syringe filter, PP filter media, Whatman, UK). The concentration of phosphate remaining in each solution was measured using a spectrophotometer (UV-2600, Shimadzu, Japan) at a wavelength of $880 \mathrm{~nm}$ according to a standard method. The adsorption amount of phosphate and the removal efficiency (\%) were calculated using the following equations:

$$
\begin{gathered}
q_{\mathrm{e}}=\frac{\left(C_{\mathrm{i}}-C_{\mathrm{e}}\right)}{m} \times V \\
\text { Removal }(\%)=\frac{\left(C_{\mathrm{i}}-C_{\mathrm{e}}\right)}{C_{\mathrm{i}}} \times 100
\end{gathered}
$$

Here, $q_{e}$ is the amount of adsorbed phosphate per unit weight of adsorbent ( $\left.\mathrm{mg} \mathrm{g}^{-1}\right), m$ is the mass of the adsorbent $(\mathrm{g}), V$ is the volume of the phosphate solution $(\mathrm{L})$, and $C_{\mathrm{i}}$ and $C_{\mathrm{e}}$ are the initial and equilibrium concentrations of phosphate $\left(\mathrm{mg} \mathrm{L}^{-1}\right)$, respectively.

The adsorption kinetics of phosphate on FCB/MAC were evaluated by preparing a series of solutions consisting of $0.25 \mathrm{~g}$ of FCB/MAC and $250 \mathrm{~mL}$ of phosphate solution ( $\mathrm{pH} \mathrm{3.0,50} \mathrm{\textrm {mg } _ { \mathrm { P } }}$ $\mathrm{L}^{-1}$ ) in plastic bottles. The mixtures were fixed in the thermostatic oscillator at $120 \mathrm{rpm}$ and $25 \pm 1{ }^{\circ} \mathrm{C}$, and $5 \mathrm{~mL}$ of the samples were removed from the mixtures at predetermined time intervals $(5,15,30,60,120,240,360,480,600$, and 720 min). The samples were immediately filtered using a nylon membrane syringe filter with a $0.45 \mu \mathrm{m}$ pore size. Adsorption equilibrium isotherms were obtained at $25 \pm 1{ }^{\circ} \mathrm{C}$ using $0.05 \mathrm{~g}$ of FCB/MAC in $50 \mathrm{~mL}$ of phosphate solutions (pH 3.0, 5-500 $\mathrm{mg}_{\mathrm{P}} \mathrm{L}^{-1}$ ) in polyethylene centrifuge tubes. After mixing for $12 \mathrm{~h}$ (sufficient to reach adsorption equilibrium), the mixtures were filtered. The amount of phosphate adsorbed on FCB/MAC under each condition was calculated using eqn (1), and the experimental results were analyzed using three kinetic models (pseudo-first-order, pseudo-second-order, and intraparticle diffusion) and five isotherm models (Langmuir, Freundlich, Langmuir-Freundlich, Redlich-Peterson, and Temkin). The expressions of the employed models are listed in Table S1. $\dagger$

The effects of coexisting anions on phosphate adsorption were evaluated by mixing $0.05 \mathrm{~g}$ of FCB/MAC with $50 \mathrm{~mL}$ of phosphate solutions $\left(\mathrm{pH} 3.0,50 \mathrm{mg}_{\mathrm{P}} \mathrm{L}^{-1}\right)$ containing equal concentrations of coexisting anions $\left(\mathrm{Cl}^{-}, \mathrm{F}^{-}, \mathrm{NO}_{3}{ }^{-}, \mathrm{SO}_{4}{ }^{2-}\right.$, and their mixture). A solution without coexisting anions was prepared as a blank. The mixtures were fixed in the thermostatic oscillator at $120 \mathrm{rpm}$ and $25 \pm 1^{\circ} \mathrm{C}$. After equilibration for $12 \mathrm{~h}$, each mixture was filtered and the phosphate concentration was analyzed.

\subsection{Phosphate desorption and reusability tests}

To evaluate the recyclability of FCB/MAC, the exhausted adsorbent was collected from the solution using an ordinary magnet after the adsorption equilibrium was reached under the following conditions: adsorbent dosage $=0.05 \mathrm{~g}$, initial phosphate concentration $=50 \mathrm{mg} \mathrm{L}^{-1}$, solution $\mathrm{pH}=3.0$, working volume $=50 \mathrm{~mL}$, and contact time $=12 \mathrm{~h}$. Then, the collected adsorbent was immersed in $\mathrm{NaOH}$ solutions with different concentrations $(0.005,0.01,0.05,0.1$, and $0.5 \mathrm{M})$ and the mixtures were stirred at $120 \mathrm{rpm}$ for $12 \mathrm{~h}$ to desorb phosphate from the adsorbent. Finally, the desorbed phosphate concentrations were measured and the desorption efficiency (\%) was calculated using the following equation:

$$
\text { Removal }(\%)=\frac{C_{\mathrm{d}} \times V_{\mathrm{d}}}{\left(C_{\mathrm{i}}-V_{\mathrm{e}}\right) \times V} \times 100
$$

where $C_{\mathrm{d}}$ and $V_{\mathrm{d}}$ are the desorbed phosphate concentration (mg $\mathrm{L}^{-1}$ ) and the volume of solution (L) during the desorption test, respectively. In this study, each recyclability test consisted of five adsorption-desorption cycles.

\section{Results and discussion}

\subsection{General characteristics of FCB/MAC}

The physicochemical properties of the prepared biochar samples are presented in Table 1 . Compared with raw biochar, the $\mathrm{C}$ and $\mathrm{O}$ contents of $\mathrm{FCB} / \mathrm{MAC}$ decreased after $\mathrm{Fe}_{3} \mathrm{O}_{4}$ and $\mathrm{Mg}-\mathrm{Al} \mathrm{LDH}$ introduction, and the BET surface area and total pore volume of the biochar composite also decreased. In addition, the doping contents of $\mathrm{Fe}, \mathrm{Mg}$, and $\mathrm{Al}$ in $\mathrm{FCB} / \mathrm{MAC}$ were 9.23, 18.97, and $7.09 \mathrm{wt} \%$, respectively, and the atomic ratio between $\mathrm{Mg}$ and $\mathrm{Al}$ was approximately 3 . Thus, the presence of magnetic $\mathrm{Fe}_{3} \mathrm{O}_{4}$ and the $\mathrm{Mg}-\mathrm{Al} \mathrm{LDH}$ were confirmed indirectly. The XRD pattern displayed sharp and symmetric principal diffraction peaks at low $2 \theta$ angles, in good agreement with those of clay minerals containing an LDH and synthetic wellcrystallized hydrotalcite-like compounds (Fig. 1a). The diffraction peaks observed at $2 \theta=11.3^{\circ}(003), 23.0^{\circ}(006), 35.6^{\circ}(009)$, 
and $61.2^{\circ}(110)$ corresponded to the characteristic peaks of a Mg-Al LDH (JCPDS no. 50-1684). The interlayer spacing of the (003) plane (d003) was $0.7834 \mathrm{~nm}$ and d006 was $0.3912 \mathrm{~nm}$, which is consistent with the values reported in the literature. ${ }^{22-24}$ The peaks at $2 \theta=30.1^{\circ}(220), 43.1^{\circ}(400), 53.5^{\circ}(422)$, $57.0^{\circ}(511)$, and $74.1^{\circ}$ (533) were consistent with the characteristic peaks of $\mathrm{Fe}_{3} \mathrm{O}_{4}$ (JCPDS no. 19-0629). The sharpness and intensity of the peaks indicated that FCB/MAC had a highly crystalline structure. Thus, the XRD analysis confirmed the successful synthesis of FCB/MAC, which is in good agreement with the subsequent FT-IR spectral analysis.

FT-IR spectroscopy was used to further identify specific functional groups in FCB/MAC (Fig. 1b). The broad bands at 3435 and $1634 \mathrm{~cm}^{-1}$ are attributed to the stretching vibrations of $\mathrm{OH}$ groups in the brucite-like layer and the bending vibrations of water molecules in the interlayer, respectively. The band at $1384 \mathrm{~cm}^{-1}$ is assigned to the vibration mode of $\mathrm{CO}_{2}{ }^{3-}$, which suggested that $\mathrm{CO}_{2}{ }^{3-}$ was successfully introduced into the interlayer of the $\mathrm{Mg}-\mathrm{Al} \mathrm{LDH}$ by the absorption of $\mathrm{CO}_{2}$ during the preparation procedure..$^{25,26}$ Moreover, the bands between 500 and $700 \mathrm{~cm}^{-1}$ are attributed to the characteristic lattice vibrations of $\mathrm{MgO}$ and $\mathrm{Al}_{2} \mathrm{O}_{3}$. Therefore, the FT-IR spectral analysis confirmed the presence of intercalated $\mathrm{CO}_{3}{ }^{2-}$ and water molecules in the $\mathrm{LDH}$ interlayer.

To determine the magnetism of FCB/MAC, the magneticfield-dependent behavior was measured using a VSM at room temperature. As shown in Table 1, the specific saturation magnetization $\left(M_{\mathrm{s}}\right)$ of FCB/MAC was $32.9 \mathrm{emu}^{-1}$, which is lower than the reported value of bulk $\mathrm{Fe}_{3} \mathrm{O}_{4}$, i.e., $92 \mathrm{emu}^{-1} .^{27}$ The reduction of the $M_{\mathrm{s}}$ value of FCB/MAC is mainly attributable to the smaller size of $\mathrm{Fe}_{3} \mathrm{O}_{4}$ nanoparticles and the relatively low amount of $\mathrm{Fe}_{3} \mathrm{O}_{4}$ loaded on $\mathrm{FCB} / \mathrm{MAC}$. The magnetic remanence $\left(M_{\mathrm{r}}\right)$ of FCB/MAC was almost zero. This small $M_{\mathrm{r}}$ value indicates that FCB/MAC exhibited superparamagnetic behavior. Interestingly, the magnetic nanocomposites suspended in aqueous solution could be easily collected and separated by a nearby permanent magnet (inset digital picture, Fig. S1 $\dagger$ ).

The comprehensive elemental composition and electronic states of FCB/MAC were investigated using XPS (Fig. 2). The XPS spectra of FCB/MAC revealed that iron, magnesium, aluminum, carbon, oxygen, and chlorine were the predominant elements. The photoelectron lines at binding energy $\left(E_{\mathrm{B}}\right)$ values of approximately 711.0, 1303.3, 74.5, 284.1, 531.8, and $200.5 \mathrm{eV}$ were attributed to $\mathrm{Fe} \mathrm{2p,} \mathrm{Mg} \mathrm{1s,} \mathrm{Al} \mathrm{2p,} \mathrm{C} \mathrm{1s,} \mathrm{O} \mathrm{1s,} \mathrm{and} \mathrm{Cl} 2 \mathrm{p}$, respectively (Fig. 2a). Furthermore, a $\mathrm{P}$ 2p peak with a binding energy of $133.6 \mathrm{eV}$ was clearly observed for phosphate-loaded FCB/MAC, which demonstrated the successful adsorption of phosphate on FCB/MAC. The XPS analysis further confirmed the presence of magnetite on the surface of FCB/MAC. In the Fe 2p spectrum (Fig. 2b), the peaks at 710.8 and $724.4 \mathrm{eV}$ were attributed to $\mathrm{Fe} 2 \mathrm{p}_{3 / 2}$ and $\mathrm{Fe} 2 \mathrm{p}_{1 / 2}$, respectively. ${ }^{\mathbf{2 8 , 2 9}}$ The spinorbital splitting of the Fe $2 p$ peak was broad owing to the small chemical shift between $\mathrm{Fe}^{2+}$ and $\mathrm{Fe}^{3+}$, both of which are present in $\mathrm{Fe}_{3} \mathrm{O}_{4} \cdot{ }^{30}$ The absence of a satellite peak at approximately $719 \mathrm{eV}$, a characteristic of $\mathrm{Fe}_{2} \mathrm{O}_{3}$, was indicative of the formation of a $\mathrm{Fe}_{3} \mathrm{O}_{4}$ phase in $\mathrm{FCB} / \mathrm{MAC}$, in good agreement with the XRD results. ${ }^{31}$

The morphological and structural features of biochar (Fig. 3a) and FCB/MAC (Fig. 3b) were characterized by SEM. The biochar surface was relatively smooth with some cracks and pores. After the two-step electro-assisted modification process, some thin layered flocculent materials and small particles were dispersed on the surface of $\mathrm{FCB} / \mathrm{MAC}$, which were presumably the $\mathrm{Mg}-\mathrm{Al} \mathrm{LDH}$ and magnetic $\mathrm{Fe}_{3} \mathrm{O}_{4}$ particles. SEM-EDS elemental mapping further confirmed the presence of $\mathrm{Fe}_{3} \mathrm{O}_{4}$ and the Mg-Al LDH on the biochar surface, as shown in Fig. 3c, as $\mathrm{O}, \mathrm{Cl}, \mathrm{Fe}, \mathrm{Mg}$, and $\mathrm{Al}$ were clearly distributed on the FCB/MAC surface.

\subsection{Effect of $\mathbf{p H}$ on phosphate adsorption}

Generally, $\mathrm{pH}$ is considered an important parameter that influences the adsorption properties at water-adsorbent interfaces. The phosphate adsorption capacities of FCB/MAC and the final solution $\mathrm{pH}$ (the $\mathrm{pH}$ of the solution after adsorption equilibrium) within the $\mathrm{pH}$ range $3.0-11.0$ are shown in Fig. S2a. $\uparrow$ It was clearly found that the adsorption of phosphate on FCB/MAC was highly dependent on the solution $\mathrm{pH}$ and the maximum adsorption amount of phosphate gradually decreased with the increase of the solution $\mathrm{pH}$ value from 3 to 11. Therefore, the ideal $\mathrm{pH}$ value was chosen as 3. Furthermore, to determine whether any dissolution of $\mathrm{Fe}, \mathrm{Mg}$, and $\mathrm{Al}$ from FCB/MAC occurred during utilization, $0.05 \mathrm{~g}$ of FCB/MAC was immersed in $50 \mathrm{~mL}$ of DI water at $\mathrm{pH} 3.0$ or 11.0 for $12 \mathrm{~h}$. The ICP-MS results showed that no $\mathrm{Fe}, \mathrm{Mg}$, or $\mathrm{Al}$ could be detected in the supernatant, indicating that these elements were strongly bound in the biochar matrix. Thus, FCB/MAC exhibited excellent stability in both acidic and basic solutions. ${ }^{32}$

When the solution $\mathrm{pH}$ is lower than the point of zero charge $\left(\mathrm{pH}_{\mathrm{pzc}}\right)$, the surface of the adsorbent is protonated and becomes more positively charged with decreases in $\mathrm{pH}$, which would promote the adsorption of phosphate anions. However, at $\mathrm{pH}$ values higher than the $\mathrm{pH}_{\mathrm{pzc}}$, phosphate adsorption on the adsorbent would be inhibited owing to increased electrostatic repulsion between the adsorbent and phosphate ions. Moreover, with further increases in the solution $\mathrm{pH}$, the hydroxyl ions would complete with phosphate species for the adsorption sites on the adsorbent surface, which would further reduce

Table 1 Physiochemical properties of the prepared biochar materials

\begin{tabular}{|c|c|c|c|c|c|c|c|c|c|}
\hline Material & $\mathrm{C}(\mathrm{wt} \%)$ & $\mathrm{O}(\mathrm{wt} \%)$ & $\mathrm{Cl}(\mathrm{wt} \%)$ & $\mathrm{Fe}(\mathrm{wt} \%)$ & $\mathrm{Mg}(\mathrm{wt} \%)$ & $\mathrm{Al}(\mathrm{wt} \%)$ & $\begin{array}{l}\text { Surface area } \\
\left(\mathrm{m}^{2} \mathrm{~g}^{-1}\right)\end{array}$ & $\begin{array}{l}\text { Total pore volume } \\
\left(\mathrm{cm}^{3} \mathrm{~g}^{-1}\right)\end{array}$ & $\begin{array}{l}\text { Saturated magnetization } \\
\left(\mathrm{emu} \mathrm{g}^{-1}\right)\end{array}$ \\
\hline Raw biochar & 58.43 & 26.67 & 13.68 & - & 1.22 & - & 133.49 & 0.09 & - \\
\hline
\end{tabular}


(a)

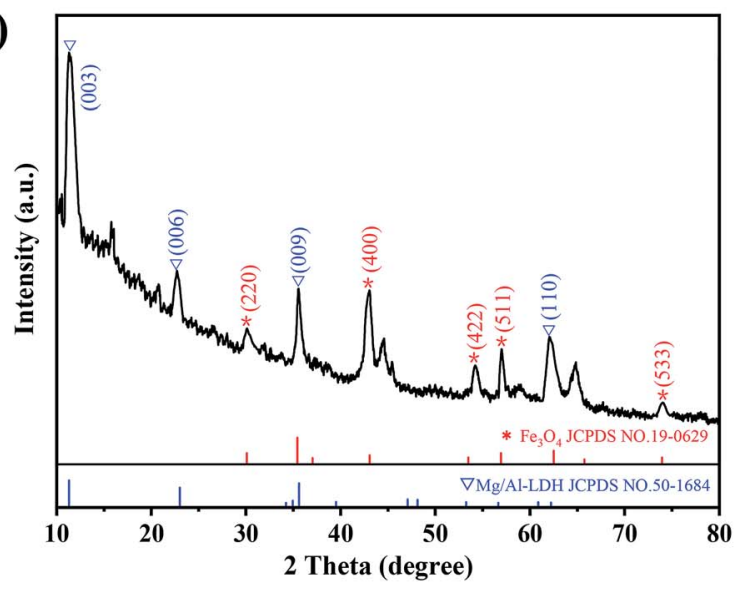

(b)

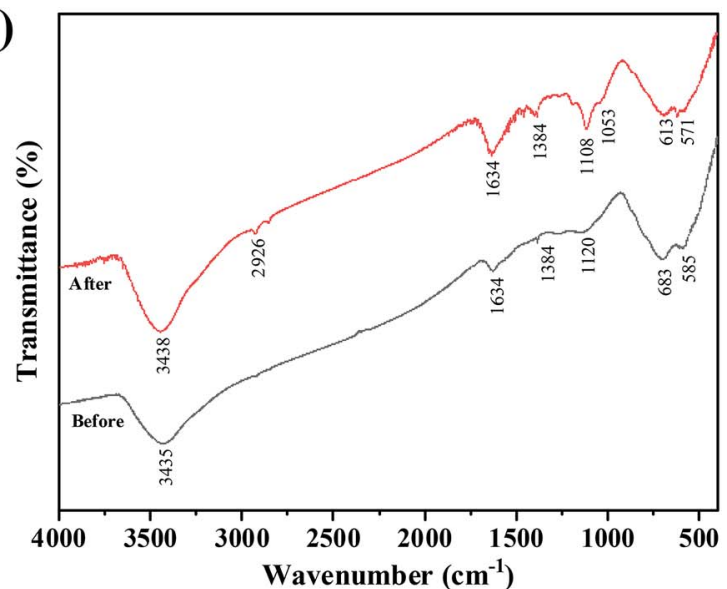

Fig. 1 (a) XRD pattern, (b) FT-IR spectra data for FBC/MAC before and after phosphate adsorption.

phosphate adsorption. ${ }^{\mathbf{1 0 , 1 1}}$ To clarify the influence of $\mathrm{pH}$ on phosphate adsorption, the zeta potential values of FCB/MAC were measured at different $\mathrm{pH}$ values. As shown in Fig. S2b, $\uparrow$ the $\mathrm{pH}_{\mathrm{pzc}}$ of $\mathrm{FCB} / \mathrm{MAC}$ is approximately 8.21. Therefore, within the $\mathrm{pH}$ range 3.0-7.0, $\mathrm{FCB} / \mathrm{MAC}$ was protonated and positively charged, which would promote the adsorption of phosphate species $\mathrm{H}_{2} \mathrm{PO}_{4}{ }^{-}$or $\mathrm{HPO}_{4}{ }^{2-}$ via electrostatic attraction, leading to a higher amount of adsorbed phosphate. However, when the $\mathrm{pH}$ was further increased, FCB/MAC was deprotonated and became negatively charged, which would decrease the phosphate adsorption capacity. ${ }^{33}$ Overall, these results indicated that electrostatic attraction plays an important role in the phosphate adsorption behavior of FCB/MAC.

\subsection{Effect of coexisting anions on phosphate adsorption}

To investigate the effect of coexisting anions on the phosphate adsorption, adsorption experiments were conducted using phosphate solutions ( $\mathrm{pH} 3,50 \mathrm{mg}_{\mathrm{P}} \mathrm{L}^{-1}$ ) with equal concentrations of competing anions (Fig. 4). It was obvious that the presence of $\mathrm{Cl}^{-}, \mathrm{NO}_{3}{ }^{-}$, and $\mathrm{SO}_{4}{ }^{2-}$ had a negligible influence on phosphate adsorption, as the amount of phosphate adsorbed by FCB/MAC was only reduced by $0.8,1.3$, and $0.7 \mathrm{mg} \mathrm{g}^{-1}$, respectively. These anions had an insignificant effect on the phosphate adsorption process because of the strong and stable interactions between the LDH and phosphate, including electrostatic attraction, anion exchange, and the formation of innersphere complexes with metal hydroxides. ${ }^{34,35}$ Compared with $\mathrm{Cl}^{-}, \mathrm{NO}_{3}{ }^{-}$, and $\mathrm{SO}_{4}{ }^{2-}, \mathrm{F}^{-}$had a more negative influence on phosphate adsorption, with the amount of phosphate adsorbed reduced by 3.9 and $5.7 \mathrm{mg} \mathrm{g}^{-1}$ for $\mathrm{F}^{-}$and an anion mixture, respectively. The inhibition of phosphate adsorption by $\mathrm{F}^{-}$is likely due to strong competition between phosphate and $\mathrm{F}^{-}$for the binding sites on the adsorbent surface. Similar results have been previously observed for other adsorbents. ${ }^{32}$ However, overall, coexisting anions have little influence on phosphate adsorption on FCB/MAC. Thus, the selectivity of this adsorbent for phosphate is high, which is important for practical applications.

\subsection{Adsorption kinetics}

The amounts of phosphate adsorbed on FCB/MAC as a function of contact time are shown in Fig. 5a. Clearly, phosphate adsorption on FCB/MAC occurred rapidly, reaching a phosphate adsorption capacity of $40.1 \mathrm{mg} \mathrm{g}^{-1}$ after $2 \mathrm{~h}$, which is
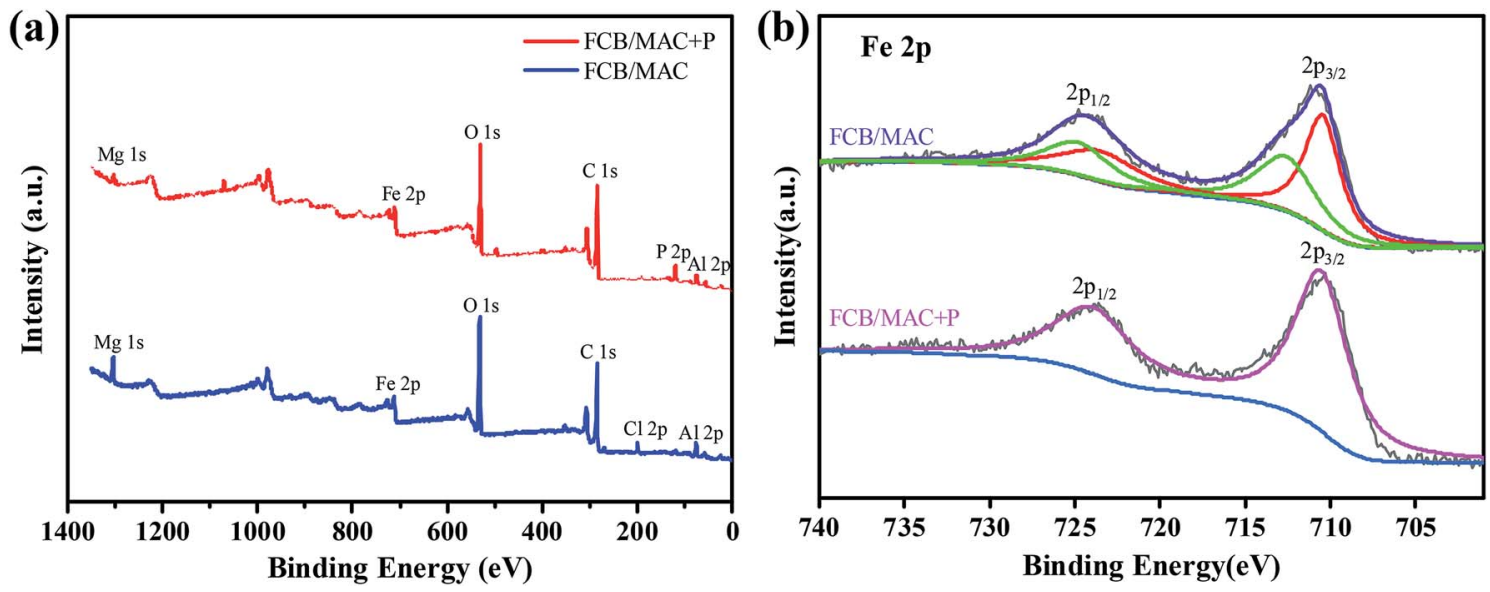

Fig. 2 The XPS spectra of FCB/MAC before and after adsorption: (a) wide spectrum, (b) Fe 2p. 

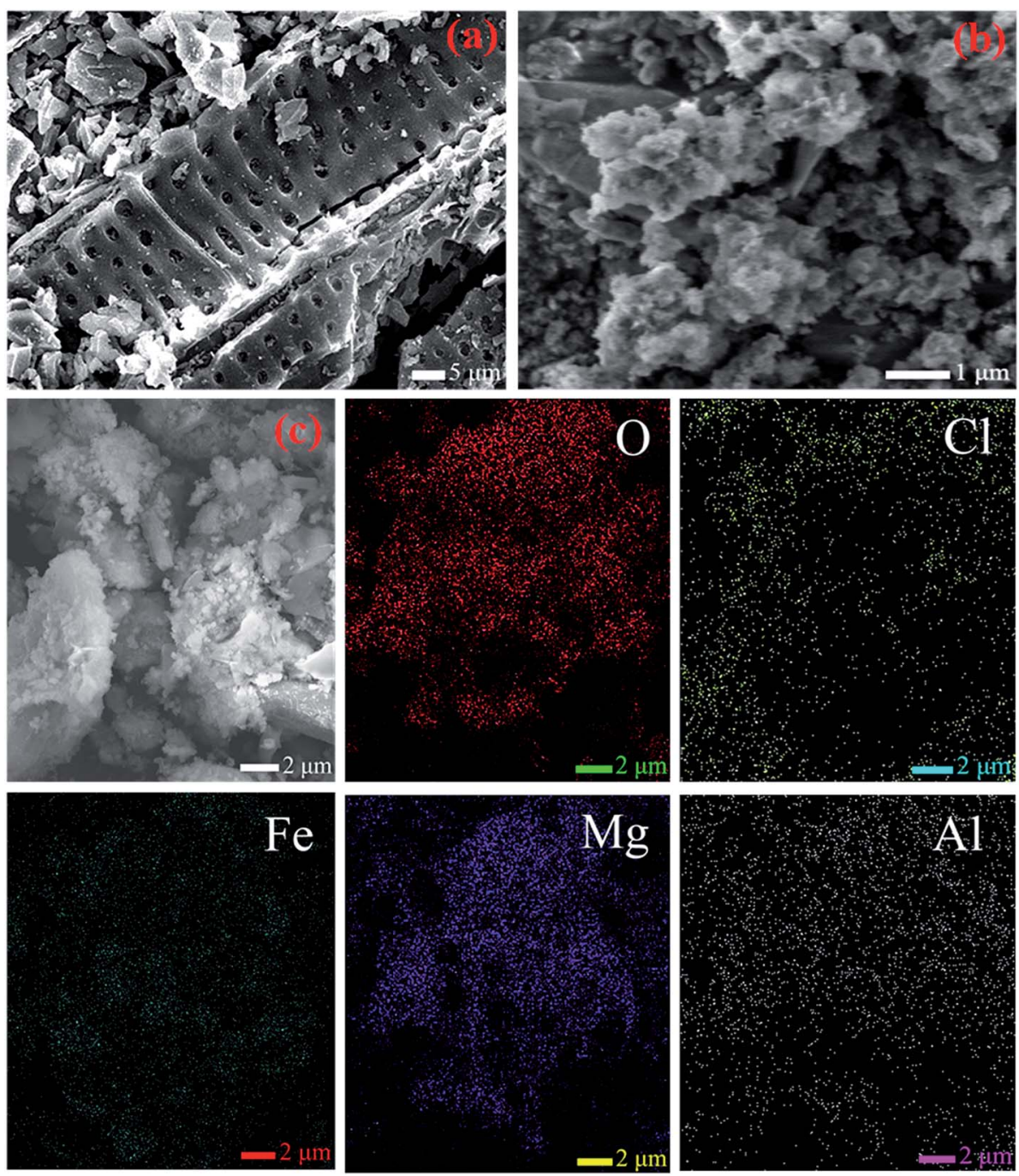

Fig. 3 SEM images of (a) raw biochar, (b) FCB/MAC and (c) the selected area of FCB/MAC for EDS analysis and EDS elemental mapping spectra of $\mathrm{O}, \mathrm{Cl}, \mathrm{Fe}, \mathrm{Mg}$ and $\mathrm{Al}$.

approximately $80 \%$ of the equilibrium adsorption capacity. The initial rapid adsorption process could be attributed to electrostatic attraction, which led to the fast transportation of phosphate from the solution onto the surface of the adsorbent. The subsequent slow adsorption process indicated that ion exchange and ligand exchange were the dominant mechanisms of phosphate adsorption. ${ }^{\mathbf{1 , 3 6}}$

The kinetic data for phosphate adsorption were analyzed using pseudo-first-order, pseudo-second-order, and intraparticle diffusion models. The fitting curves for the pseudo-firstorder and pseudo-second-order models are presented in Fig. 5a and the kinetic parameters obtained using these two kinetic models are summarized in Table 2. It was found that the correlation coefficient $\left(R^{2}\right)$ of the pseudo-second-order kinetic model was higher than that of the pseudo-first-order kinetic model, suggesting that the phosphate adsorption process was better described by the pseudo-second-order kinetic model.

More importantly, as clearly shown in Fig. 5b, the adsorption kinetics (plots of $q_{\mathrm{e}}$ versus $t^{1 / 2}$ ) exhibited multilinearity. The first region is sharper and quicker, which can be ascribed to the presence of many available adsorption sites in the adsorbent and a relativity high concentration of phosphate in the solution. ${ }^{37}$ Then, the second region represents phosphate molecules diffusing into the pores of the adsorbent, suggesting that intraparticle diffusion is the rate-limiting step of this stage. Finally, the third region can be attributed to the equilibrium stage, where intraparticle diffusion becomes slow owing to the low phosphate concentration in the solution. ${ }^{38}$ In addition, the multilinear plots indicate that two or more steps (multistep adsorption) occur during the phosphate adsorption process on FCB/MAC. The kinetic parameters obtained from the kinetic models (Table 2) show that the intraparticle diffusion model fits the experimental data well $\left(R^{2}=0.99\right)$. This finding indicates that intraparticle diffusion is involved in the adsorption process but other mechanisms also play an important role. Therefore, the kinetic and intraparticle diffusion analyses confirmed that the overall behavior of the phosphate adsorption process on FCB/MAC is likely controlled by multiple parallel processes, 


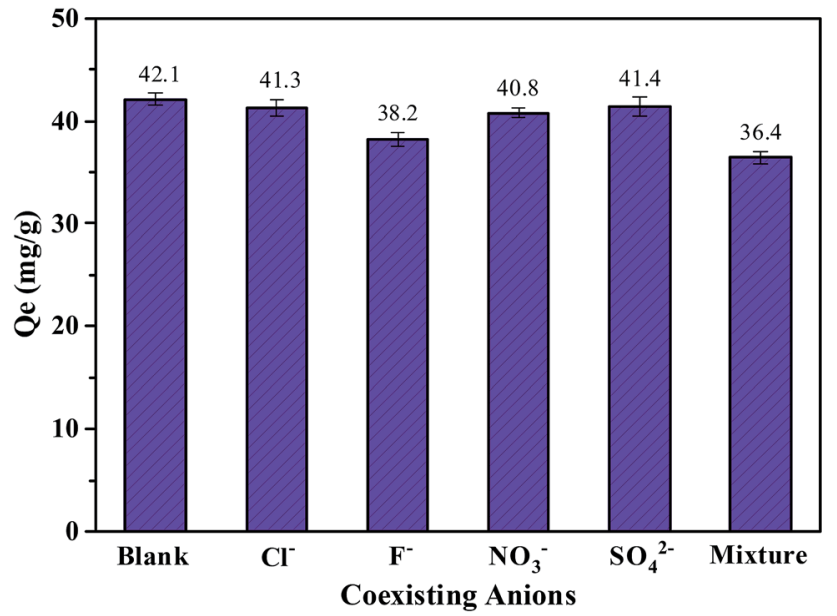

Fig. 4 Effect of coexisting anions on the phosphate adsorption by FCB/MAC. Adsorption conditions: initial phosphate concentration, $50 \mathrm{mg} \mathrm{L}^{-1}$; solution $\mathrm{pH}, 3.0$; temperature, $25^{\circ} \mathrm{C}$; FCB/MAC dosage, $0.05 \mathrm{~g}$; working volume, $50 \mathrm{~mL}$; contact time, $12 \mathrm{~h}$.
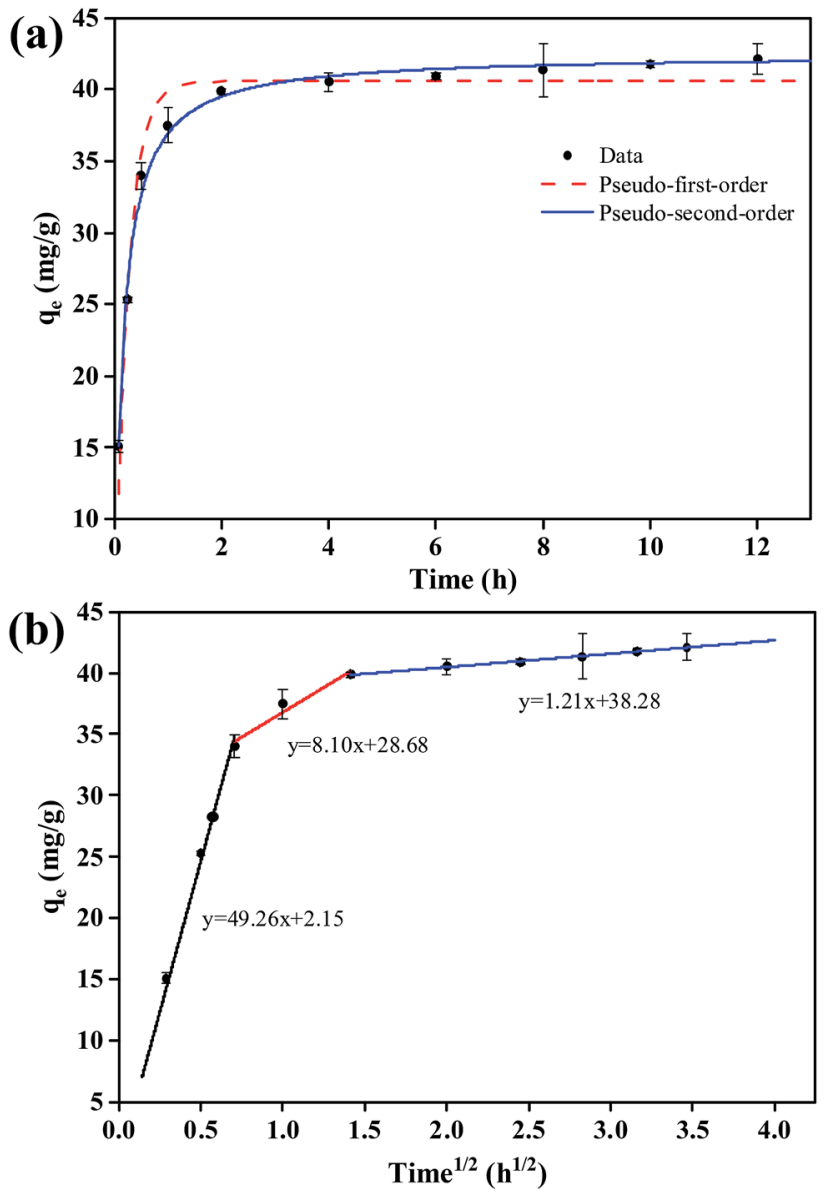

Fig. 5 Kinetics of phosphate adsorption on FCB/MAC: (a) experimental data and fitting for pseudo-first-order and pseudo-secondorder models and (b) intraparticle diffusion model. Adsorption conditions: initial phosphate concentration, $50 \mathrm{mg} \mathrm{L}^{-1}$; solution $\mathrm{pH}$, 3.0; temperature, $25^{\circ} \mathrm{C}$; FCB/MAC dosage, $0.25 \mathrm{~g}$; working volume, $250 \mathrm{~mL}$; contact time, $12 \mathrm{~h}$. involving rapid external surface adsorption and diffusion into the interior of the prepared biochar. ${ }^{39}$

\subsection{Adsorption isotherms}

The adsorption isotherms for phosphate adsorption on FCB/MAC are presented in Fig. 6. As shown, with an increase of the initial phosphate concentration, the adsorption capacity of FCB/MAC gradually increases. The related parameters calculated from the five models are listed in Table 2. Clearly, almost all the isotherm models reproduced the adsorption data well, except the Freundlich equation. However, the Langmuir-Freundlich (highest $R^{2}$ value of 0.9925) and Redlich-Peterson models matched the experimental data better than the other models, suggesting that the interaction between phosphate and FCB/MAC could be affected by both the Langmuir and Freundlich processes. This result is consistent with the kinetics study and suggests that the adsorption of phosphate on FCB/MAC is controlled by multiple processes, involving simultaneous physical and chemical adsorption. ${ }^{40,41}$

Herein, the adsorption of phosphate on FCB/MAC occurs by ion exchange with both the intercalated anions of the $\mathrm{Mg}-\mathrm{Al}$ LDH and ligand exchange reactions with the surface groups. Typically, there are three steps during the phosphate adsorption process on the Mg-Al LDH: (1) external mass transfer between the external surface of the Mg-Al LDH and the surrounding fluid phase; (2) intraparticle transport within the LDH; and (3) chemisorption. ${ }^{42}$ It has been suggested that lower molecular weight phosphates can easily enter the mesoporous $\mathrm{Mg}-\mathrm{Al} \mathrm{LDH}$ and undergo ligand exchange reactions with the surface groups. ${ }^{43}$ The synergistic interactions of the $\mathrm{Mg}-\mathrm{Al} \mathrm{LDH}$ with phosphate lead to the highly efficient adsorption of phosphate on FCB/MAC. Notably, the theoretical maximum adsorption capacity $\left(q_{\mathrm{m}}\right)$ of FCB/MAC was calculated to be $252.88 \mathrm{mg} \mathrm{g}^{-1}$ at $25 \pm 1{ }^{\circ} \mathrm{C}$ using the Langmuir-Freundlich isotherm, which far exceeds the adsorption capacity of a pure $\mathrm{Fe}_{3} \mathrm{O}_{4} @ \mathrm{Mg}-\mathrm{Al} \mathrm{LDH}$, as reported by Yan $e t a l .{ }^{44}$ These results clearly indicated that FCB/MAC is a promising adsorbent for phosphate adsorption. The significant increase of phosphate adsorption achieved by grafting an $\mathrm{LDH}$ on a $\mathrm{Fe}_{3} \mathrm{O}_{4}$ magnetic biochar compared with magnetic biochars modified with single metals suggested that the combination of metal modification and the positively charged Mg-Al LDH provides considerably enhanced anion adsorption. For comparison, Table 3 lists the phosphate adsorption capacities of other adsorbents, such as magnetiteparticle-grafted orange peel biochar $\left(1.24 \mathrm{mg} \mathrm{g}^{-1}\right),{ }^{7} \mathrm{MgO}-$ impregnated magnetic biochar $\left(121.25 \mathrm{mg} \mathrm{g}^{-1}\right),{ }^{8} \mathrm{La}(\mathrm{OH})_{3^{-}}$ modified magnetic pineapple biochar $\left(101.16 \mathrm{mg} \mathrm{g}^{-1}\right),{ }^{9}$ and $\mathrm{MgFe}_{2} \mathrm{O}_{4} /$ biochar magnetic composite $\left(159.24 \mathrm{mg} \mathrm{g}^{-1}\right){ }^{10}$ Obviously, FCB/MAC is a better phosphate adsorbent than these previously reported systems.

\subsection{XPS analysis}

To further explore the sorption mechanism of phosphate on the FCB/MAC adsorbent, the adsorbent before and after phosphate adsorption was subjected to XPS analysis. Fig. 7 shows the P 2p, $\mathrm{O} 1 \mathrm{~s}, \mathrm{Mg}$ 1s, and Al 2p XPS spectra. Based on the binding 
Table 2 Best-fit parameter values from model simulations of phosphate adsorption kinetics and isotherms

\begin{tabular}{llll}
\hline & Parameter 1 & Parameter 2 & Parameter 3 \\
\hline Adsorption kinetics & & & $R^{2}$ \\
Pseudo-first-order & $k_{1}=4.1160\left(\mathrm{~h}^{-1}\right)$ & $q_{\mathrm{e}}=40.5612\left(\mathrm{mg} \mathrm{g}^{-1}\right)$ & $R^{2}=0.9615$ \\
Pseudo-second-order & $k_{2}=0.1569\left(\mathrm{~g} \mathrm{mg}^{-1} \mathrm{~h}^{-1}\right)$ & $q_{\mathrm{e}}=42.4511\left(\mathrm{mg} \mathrm{g}^{-1}\right)$ & $R^{2}=0.9932$ \\
Intraparticle diffusion & $k_{\mathrm{i} 1}=49.2608\left(\mathrm{mg} \mathrm{g}^{-1} \mathrm{~h}^{1 / 2}\right)$ & $C_{1}=2.1493\left(\mathrm{mg} \mathrm{g}^{-1}\right)$ & $R^{2}\left(k_{\mathrm{i} 1}\right)=0.9785$ \\
& $k_{\mathrm{i} 2}=8.1021\left(\mathrm{mg} \mathrm{g}^{-1} \mathrm{~h}^{1 / 2}\right)$ & $C_{2}=28.6793\left(\mathrm{mg} \mathrm{g}^{-1}\right)$ & $R^{2}\left(k_{\mathrm{i} 2}\right)=0.9149$ \\
& $k_{\mathrm{i} 3}=1.0951\left(\mathrm{mg} \mathrm{g}^{-1} \mathrm{~h}^{1 / 2}\right)$ & $C_{3}=38.2825\left(\mathrm{mg} \mathrm{g}^{-1}\right)$ & \\
& & & \\
Adsorption isotherms & & $Q_{\mathrm{m}}=248.6390\left(\mathrm{mg} \mathrm{g}^{-1}\right)$ & \\
Langmuir & $K_{\mathrm{L}}=0.0464\left(\mathrm{~L} \mathrm{mg}^{-1}\right)$ & $1 / n=0.2921$ & $R^{2}=0.9916$ \\
Freundlich & $K_{\mathrm{F}}=49.4181\left(\mathrm{mg} \mathrm{g}^{-1}\right)$ & $Q_{\mathrm{m}}=252.8803\left(\mathrm{mg} \mathrm{g}^{-1}\right)$ & $1 / n=0.9368$ \\
Langmuir-Freundlich & $K_{\mathrm{LF}}=0.0537\left(\mathrm{~L} \mathrm{mg}^{-1}\right)$ & $a=0.0375\left(\mathrm{~L} \mathrm{mg}^{-1}\right)$ & $1 / n=0.9566$ \\
Redlich-Peterson & $K_{\mathrm{R}}=12.1571\left(\mathrm{~L} \mathrm{mg}^{-1}\right)$ & $a=1.8360\left(\mathrm{~L} \mathrm{mg}^{-1}\right)$ & $R^{2}=0.8948$ \\
Temkin & $b=0.0964\left(\mathrm{~J} \mathrm{~g} \mathrm{mg}^{-1}\right)$ & & $R^{2}=0.9925$ \\
& & & $R^{2}=0.9173$ \\
\end{tabular}

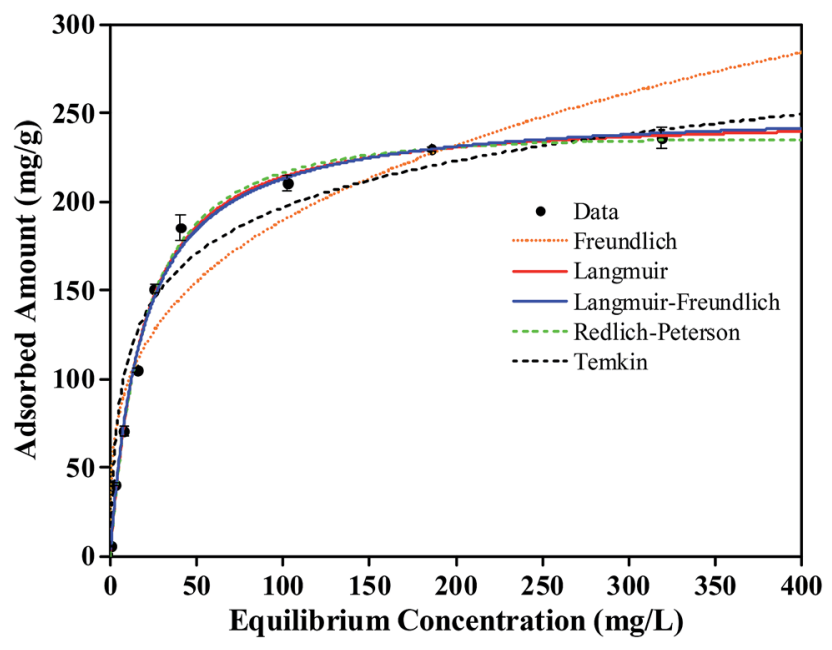

Fig. 6 Adsorption isotherm data and modeling for phosphate on the FCB/MAC. Symbols are experimental data, and lines are model results. Adsorption conditions: initial phosphate concentration range, 5$500 \mathrm{mg} \mathrm{L}^{-1}$; solution $\mathrm{pH}, 3.0$; temperature, $25^{\circ} \mathrm{C}$; FCB/MAC dosage, $0.05 \mathrm{~g}$; working volume, $50 \mathrm{~mL}$; contact time, $12 \mathrm{~h}$. energies of various phosphorus species, the P 2p XPS spectra (Fig. 7a) could be divided into two peaks corresponding to $\mathrm{M}-\mathrm{P}$ (phosphorus bonded to metal) and $\mathrm{M}-\mathrm{O}-\mathrm{P}$ (phosphorus bonded to metal oxide), indicating a strong affinity between phosphate and FCB/MAC. For the pristine adsorbent, the $\mathrm{O} 1 \mathrm{~s}$ XPS spectrum (Fig. 7b) could be fitted to three peaks, namely, $\mathrm{O}^{2-}$ at $529.5 \mathrm{eV}, \mathrm{OH}^{-}$at $530.4 \mathrm{eV}$, and $\mathrm{CO}_{3}{ }^{2-}$ at $531.4 \mathrm{eV}{ }^{\mathbf{1 6 , 4 5 , 4 6}}$ After phosphate adsorption, the area ratio of $\mathrm{O}^{2-}$ decreased from $26.40 \%$ to $26.05 \%$, likely owing to the group exchange of $\mathrm{M}-\mathrm{O}$ (oxygen bonded to metal) with phosphate. The area ratio of $\mathrm{CO}_{3}{ }^{2-}$ also decreased from $37.89 \%$ to $31.5 \%$, likely owing to the exchange of phosphate with $\mathrm{CO}_{3}{ }^{2-}$. Furthermore, the area ratio of $\mathrm{OH}^{-}$increased from $35.71 \%$ to $42.45 \%$, corresponding to the one or two $\mathrm{P}-\mathrm{OH}$ groups contributed by different $\mathrm{H}_{2} \mathrm{PO}_{4}{ }^{-}$/ $\mathrm{HPO}_{4}{ }^{2-}$ species. ${ }^{17}$ Thus, it is believed that the metal hydroxyl sites are capable of ligand exchange with the target phosphates. The Mg 1s and Al 2p XPS spectra of FCB/MAC are displayed in Fig. $7 \mathrm{c}$ and d, respectively. The binding energy of $\mathrm{Mg} 1 \mathrm{~s}$ changed from 1304.3 to $1303.6 \mathrm{eV}$, whereas that of $\mathrm{Al} 2 \mathrm{p}$ changed from 74.9 to $75.7 \mathrm{eV}$, illustrating that the $\mathrm{Mg}$ and $\mathrm{Al}$ metal hydroxides participated in the adsorption process. ${ }^{16}$ Furthermore, the Fe $2 \mathrm{p}$

Table 3 Comparison of phosphate adsorption capacities with other reported adsorbents ${ }^{a}$

\begin{tabular}{|c|c|c|c|c|c|c|c|c|}
\hline Adsorbent & $\mathrm{IC}\left(\mathrm{mg} \mathrm{L}^{-1}\right)$ & $\mathrm{pH}$ & $t(\mathrm{~h})$ & $\mathrm{RT}\left({ }^{\circ} \mathrm{C}\right)$ & Isotherm & $\mathrm{AM}$ & $\mathrm{AC}\left(\mathrm{mg} \mathrm{g}^{-1}\right)$ & References \\
\hline $\begin{array}{l}\text { Magnetite particles grafted orange peel } \\
\text { biochar }\end{array}$ & $0-12$ & NR & 24 & 25 & $\mathrm{~L}$ & NR & 1.24 & 7 \\
\hline MgO-impregnated magnetic biochar & $5-500$ & 4.0 & 12 & 23 & $\mathrm{~L}$ & EA and IC & 121.25 & 8 \\
\hline $\begin{array}{l}\mathrm{La}(\mathrm{OH})_{3} \text {-modified magnetic pineapple } \\
\text { biochar }\end{array}$ & $100-400$ & NR & 24 & 30 & $\mathrm{~L}$ & EA, LE and IC & 101.16 & 9 \\
\hline $\mathrm{MgFe}_{2} \mathrm{O}_{4} /$ biochar magnetic composites & $2-163$ & 3.0 & 12 & 20 & $\mathrm{~S}$ & IC & 159.24 & 10 \\
\hline $\mathrm{La} / \mathrm{Fe}_{3} \mathrm{O}_{4}$-biochar & 75 & 6.1 & 15 & 25 & $\mathrm{D}-\mathrm{R}$ & EA and IC & 25.00 & 16 \\
\hline $\mathrm{Ce} / \mathrm{Fe}_{3} \mathrm{O}_{4}$-biochar & 75 & 6.1 & 15 & 25 & $\mathrm{~F}$ & EA and IC & 18.75 & \\
\hline $\begin{array}{l}\text { Ferric oxides loaded cotton stalks } \\
\text { biochar }\end{array}$ & 7 & NR & 24 & 25 & NR & $\mathrm{AE}$ and $\mathrm{EA}$ & 0.31 & 47 \\
\hline $\mathrm{Fe}_{3} \mathrm{O}_{4} @ \mathrm{Mg}-\mathrm{Al}$ layered double hydroxide & 13 & 3.0 & 1 & 25 & $\mathrm{~L}$ & $\mathrm{AE}, \mathrm{LE}$ and $\mathrm{EA}$ & 10.30 & 44 \\
\hline FCB/MAC & $5-500$ & 3.0 & 12 & 25 & L-F & $\mathrm{AE}, \mathrm{EA}$, and $\mathrm{LE}$ & 252.88 & This study \\
\hline
\end{tabular}

${ }^{a}$ IC, initial concentration; RT, removal temperature; L-F, Langmuir-Freundlich model; D-R, Dubinin-Radushkevich model; L, Langmuir model; F, Freundlich model; S, Sips model; AM, adsorption mechanisms; IC, inner-sphere complexation; AE, anion exchange; EA, electrostatic attraction; LE, ligand exchange; AC, adsorption capacity; NR, no report. 

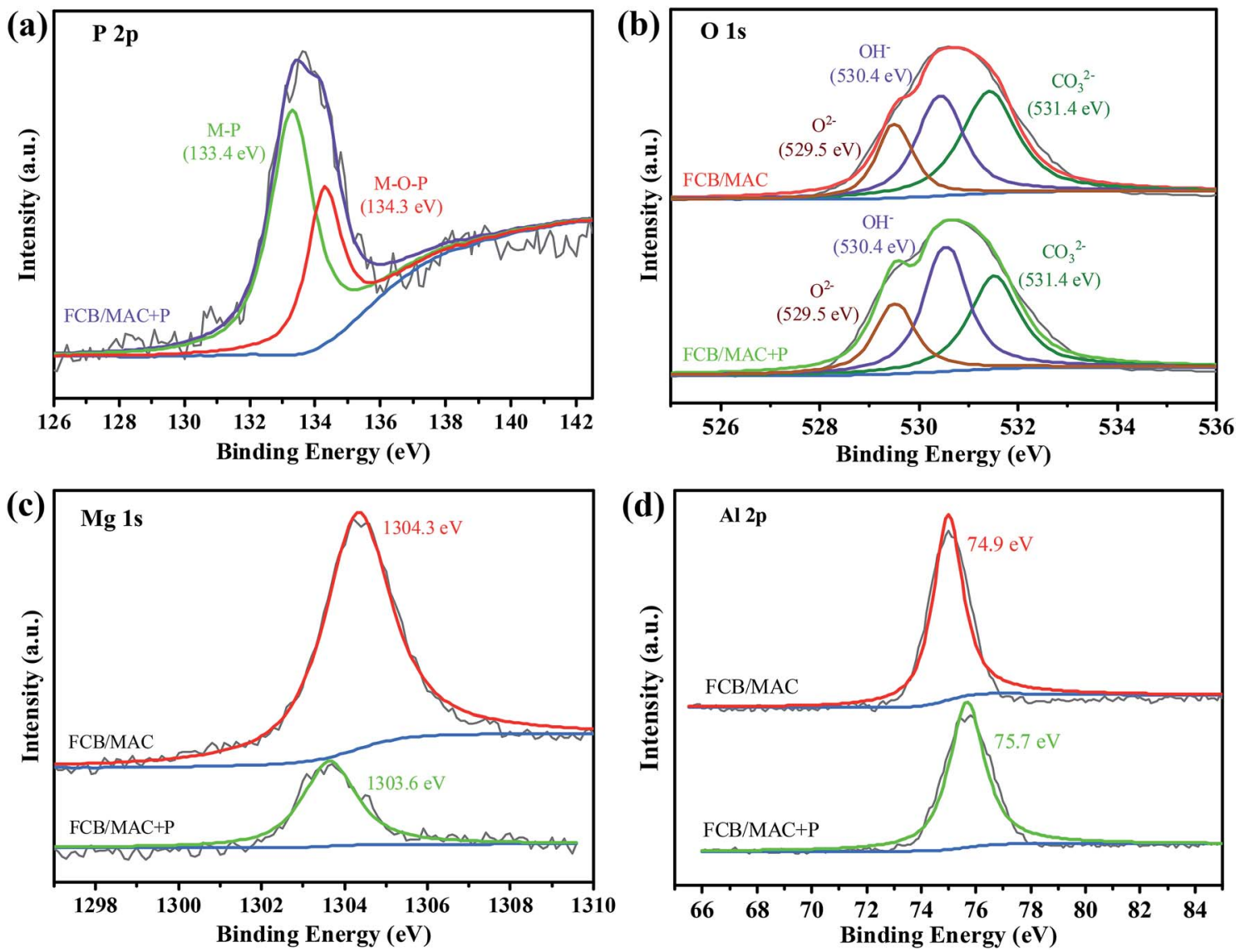

Fig. 7 (a) The XPS spectra of P 2p. The XPS analysis of the O 1s (b), Mg 1s (c), Al 2p (d) before and after phosphate adsorption.

XPS spectra (Fig. 2b) of FCB/MAC before and after adsorption were similar, indicating that the iron oxide did not participate in the adsorption process. These analyses are consistent with anion exchange and ligand exchange being involved in the phosphate adsorption process.

\subsection{Adsorbent regeneration and phosphate readsorption}

The stability and the recyclability of an adsorbent are vital for its industrial application. As mentioned in Section 3.2, the phosphate adsorption capacity of FCB/MAC decreased drastically as the solution $\mathrm{pH}$ increased. This result indicated that alkaline conditions $\left(\mathrm{pH}>\mathrm{pH}_{\mathrm{pzc}}\right)$ can facilitate the desorption of phosphate from exhausted adsorbents. Thus, the desorption of phosphate from phosphate-loaded FCB/MAC was performed at different $\mathrm{NaOH}$ concentrations $(0.005-0.5 \mathrm{M})$, and the results are shown in Fig. 8a. The desorption efficiency increased gradually from $19.95 \%$ to $81.76 \%$ with the increase of the $\mathrm{NaOH}$ concentration from 0.005 to $0.1 \mathrm{M}$. However, further increases
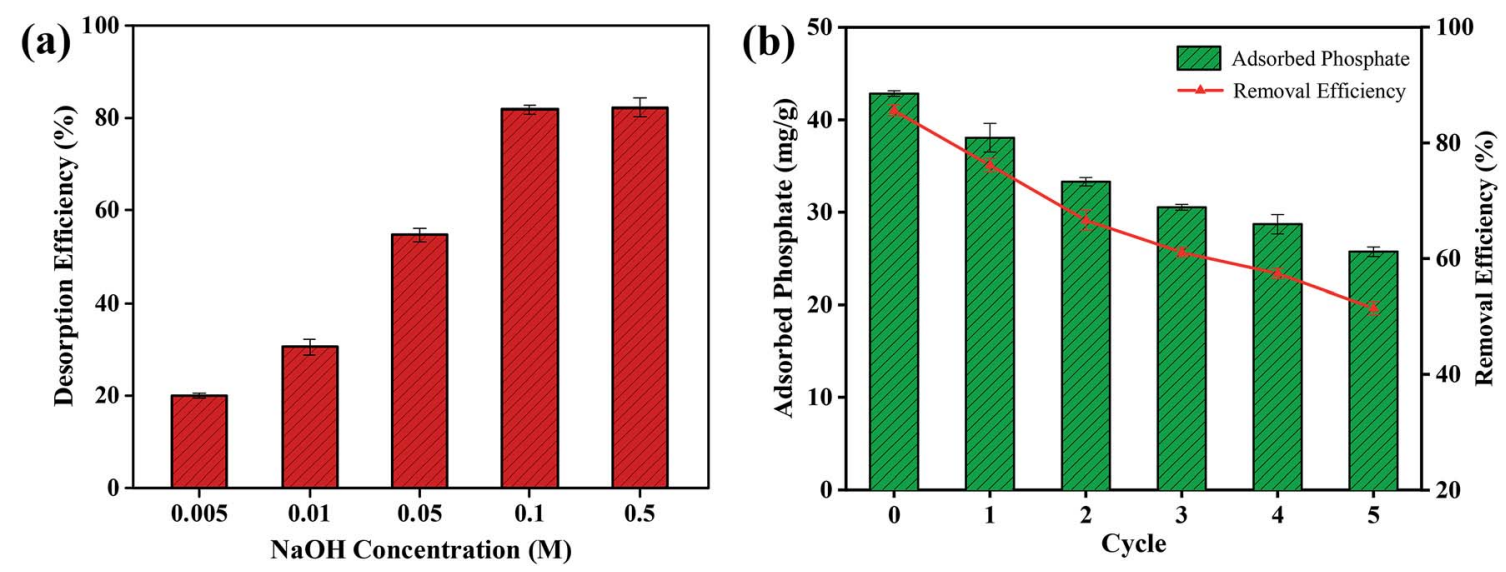

Fig. 8 (a) Desorption performance at different $\mathrm{NaOH}$ concentrations. (b) Cyclic stability of FCB/MAC regenerated by $0.1 \mathrm{M} \mathrm{NaOH}$. 
in the $\mathrm{NaOH}$ concentration had no significant effect on the desorption efficiency. Therefore, $0.1 \mathrm{M} \mathrm{NaOH}$ was chosen as the optimal condition for the regeneration process. As shown in Fig. 8b, even though the phosphate adsorption performance of FCB/MAC gradually decreased with subsequent adsorptiondesorption cycles, a certain adsorption capacity (approximately $25.71 \mathrm{mg} \mathrm{g}^{-1}$ with $51.43 \%$ removal efficiency) was still maintained after five cycles, which is better than the performance other magnetic adsorbents. Thus, the recyclability test demonstrated that FCB/MAC could be effectively separated without any weight loss using a magnetic field and easily reused by applying a $\mathrm{NaOH}$ solution as an eluent for efficient phosphate removal. Subsequently, as a suggestion for recycling of the exhausted material, the exhausted FCB/MAC can be acidified to obtain the raw biochar. The raw biochar can again be subjected to the twostep electro-assisted modification process to produce FCB/MAC, thus achieving recycling of the exhausted material.

\section{Conclusions}

FCB/MAC was successfully prepared by a two-step electroassisted modification process for the first time. This process enriches the technology that is available for modifying biochar. FCB/MAC provides an ideal combination of the adsorption features of biochar with the magnetic properties of $\mathrm{Fe}_{3} \mathrm{O}_{4}$ and the adsorption properties of $\mathrm{Mg}-\mathrm{Al} \mathrm{LDH}$. FCB/MAC showed a higher phosphate adsorption capacity $\left(252.88 \mathrm{mg} \mathrm{g}^{-1}\right)$ than most previously reported adsorbents. Furthermore, FCB/MAC showed good selectivity, as the presence of coexisting anions, including $\mathrm{Cl}^{-}, \mathrm{F}^{-}, \mathrm{NO}_{3}{ }^{-}$, and $\mathrm{SO}_{4}{ }^{2-}$, had little influence on the removal of phosphate. The adsorption kinetics of phosphate were well represented by the pseudo-second-order and intraparticle diffusion models and the adsorption isotherms were fitted best by the Langmuir-Freundlich model. The phosphate adsorption mechanism involved electrostatic attraction, ligand exchange with surface groups, and anion exchange with the interlayer anions of FCB/MAC. Phosphate-loaded FCB/MAC exhibited excellent magnetic recovery and phosphate desorption. Therefore, FCB/MAC is an optimal reusable hybrid adsorbent and has considerable potential for phosphate removal in practical applications.

\section{Conflicts of interest}

There are no conflicts to declare.

\section{Acknowledgements}

This work was supported by the National Key Research and Development Plan of China (2016YFC0501702, 2017YFC0504504), the National Natural Science Foundation of China (41571225), and Science and technology Service Network Initiative of the Chinese Academy of Sciences (KFJ-STS-ZDTP012). We also thank the instrument analysis center of Xi'an Jiaotong University (XJTU, China).

\section{References}

1 J. Lalley, C. Han, X. Li, D. D. Dionysiou and M. N. Nadagouda, Chem. Eng. J., 2016, 284, 1386-1396.

2 M. I. Inyang, B. Gao, Y. Yao, Y. Xue, A. Zimmerman, A. Mosa, P. Pullammanappallil, Y. S. OK and X. Cao, Crit. Rev. Environ. Sci. Technol., 2016, 46, 406-433.

3 S. B. Liu, X. F. Tan, Y. G. Liu, Y. L. Gu, G. M. Zeng, X. J. Hu, H. Wang, L. Zhou, L. H. Jiang and B. B. Zhao, RSC Adv., 2016, 6, 5871-5880.

4 Y. Yao, B. Gao, J. Chen, M. Zhang, M. Inyang, Y. Li, A. Alva and L. Yang, Bioresour. Technol., 2013, 138, 8-13.

5 S. Wan, S. Wang, Y. Li and B. Gao, J. Ind. Eng. Chem., 2017, 47, 246-253.

6 B. Micháleková-Richveisová, V. Frišták, M. Pipíška, L. Duriška, E. Moreno-Jimenez and G. Soja, Environ. Sci. Pollut. Res., 2016, 24, 463-475.

7 B. Chen, Z. Chen and S. Lv, Bioresour. Technol., 2011, 102, 716-723.

8 R. Li, J. J. Wang, B. Zhou, M. K. Awasthi, A. Ali, Z. Zhang, A. H. Lahori and A. Mahar, Bioresour. Technol., 2016, 215, 209-214.

9 T. Liao, T. Li, X. Su, X. Yu, H. Song, Y. Zhu and Y. Zhang, Bioresour. Technol., 2018, 263, 207-213.

10 K. W. Jung, S. Lee and Y. J. Lee, Bioresour. Technol., 2017, 245, 751-759.

11 L. Wang, J. Wang, C. He, W. Lyu, W. Zhang, W. Yan and L. Yang, Colloids Surf., A, 2019, 561, 236-243.

12 M. K. R. Reddy, Z. P. Xu, G. Q. Lu and C. J. Diniz da Costa, Ind. Eng. Chem. Res., 2006, 45, 7504-7509.

13 K. H. Goh, T. T. Lim and Z. Dong, Water Res., 2008, 42, 01368.

14 H. Pang, Y. Wu, S. Huang, C. Ding, S. Li, X. Wang, S. Yu, Z. Chen, G. Song and X. Wang, Inorg. Chem. Front., 2018, 5, 2657.

15 S. Yu, Y. Liu, Y. Ai, X. Wang, R. Zhang, Z. Chen, Z. Chen, G. Zhao and X. Wang, Environ. Pollut., 2018, 242, 1-11.

16 S. Yu, X. Wang, Y. Liu, Z. Chen, Y. Wu, Y. Liu, H. Pang, G. Song, J. Chen and X. Wang, Chem. Eng. J., 2019, 365, 51-59.

17 Q. Zhang, J. Teng, G. Zou, Q. Peng, Q. Du, T. Jiao and J. Xiang, Nanoscale, 2016, 8, 7085.

18 G. Gollavelli, C. C. Chang and Y. C. Ling, ACS Sustainable Chem. Eng., 2013, 1, 462-472.

19 S. Nethaji, A. Sivasamy and A. B. Mandal, Bioresour. Technol., 2013, 134, 94-100.

20 S. Yu, L. Yin, H. Pang, Y. Wu, X. Wang, P. Zhang, B. Hu, Z. Chen and X. Wang, Chem. Eng. J., 2018, 352, 360-370.

21 K. W. Jung, M. J. Hwang, T. U. Jeong and K. H. Ahn, Bioresour. Technol., 2015, 191, 342-345.

22 F. Cavani, F. Trifiro and A. Vaccari, Catal. Today, 1991, 11, 173-301.

23 Y. Chen, F. Li, S. Zhou, J. Wei, Y. Dai and Y. Chen, J. Solid State Chem., 2010, 183, 2222-2226.

24 S. Özgümüş, M. K. Gök, A. Bal and G. Güçlü, Chem. Eng. J., 2013, 223, 277-286. 
25 Y. Li, B. Gao, T. Wu, D. Sun, X. Li, B. Wang and F. Lu, Water Res., 2009, 43, 3067-3075.

26 L. Li, R. Li, S. Gai, F. He and P. Yang, J. Mater. Chem. A, 2014, 2, 8758-8765.

27 X. Peng, Z. Luan and H. Zhang, Chemosphere, 2006, 63, 300306.

28 F. R. Costa, A. Leuteritz, U. Wagenknecht, M. A. D. Landwehr, D. Jehnichen, L. Haeussler and G. Heinrich, Appl. Clay Sci., 2009, 44, 7-14.

29 X. Lu, Y. Yu, L. Chen, H. Mao, H. Gao, J. Wang and W. Yen, Nanotechnology, 2005, 16, 1660-1665.

30 S. Shanmugam, T. Nakanishi and T. Osaka, J. Electrochem. Soc., 2009, 156, K121-K127.

31 D. Zhang, Z. Liu, S. Han, C. Li, B. Lei, M. P. Stewart, J. M. Tour and C. Zhou, Nano Lett., 2004, 4, 2151-2155.

32 R. Li, J. J. Wang, B. Zhou, M. K. Awasthi, A. Ali, Z. Zhang, L. A. Gaston, A. H. Lahori and A. Mahar, Sci. Total Environ., 2016, 559, 121-129.

33 B. Wu, L. Fang, J. D. Fortner, X. Guan and I. M. C. Lo, Water Res., 2017, 126, 179-188.

34 F. Hu, M. Wang, X. Peng, F. Qiu, T. Zhang, H. Dai, Z. Liu and Z. Cao, Colloids Surf., A, 2018, 555, 314-323.

35 J. Lu, H. Liu, X. Zhao, W. Jefferson, F. Cheng and J. Qu, Colloids Surf., A, 2014, 455, 11-18.

36 J. Lü, H. Liu, R. Liu, X. Zhao, L. Sun and J. Qu, Powder Technol., 2013, 233, 146-154.
37 M. Ghaedi, A. Hassanzadeh and S. N. Kokhdan, J. Chem. Eng. Data, 2011, 56, 2511-2520.

38 S. Karaca, A. Gürses, M. Ejder and M. Açikyildiz, J. Colloid Interface Sci., 2004, 277, 257-263.

39 G. Crini, H. N. Peindy, F. Gimbert and C. Robert, Sep. Purif. Technol., 2007, 53, 97-110.

40 C. Fang, T. Zhang, P. Li, R. F. Jiang and Y. C. Wang, Int. J. Environ. Res. Public Health, 2014, 11, 9217-9237.

41 Y. Yao, B. Gao, M. Inyang, A. R. Zimmerman, X. Cao, P. Pullammanappallil and L. Yang, J. Hazard. Mater., 2011, 190, 501-507.

42 M. S. Gasser, H. T. Mohsen and H. F. Aly, Colloids Surf., A, 2008, 331, 195-201.

43 Z. P. Xu and G. Q. Lu, Chem. Mater., 2005, 17, 1055-1062.

44 L. G. Yan, K. Yang, R. R. Shan, T. Yan, J. Wei, S. J. Yu, H. Q. Yu and B. Du, J. Colloid Interface Sci., 2015, 448, 508516.

45 J. Chen, Y. Song, D. Shan and E. Han, Corros. Sci., 2012, 63, 148-158.

46 Q. Zhang, S. Bolisetty, Y. Cao, S. Handschin, J. Adamcik, Q. Peng and R. Mezzenga, Angew. Chem., Int. Ed., 2019, 58, 6012-6016.

47 J. Ren, N. Li, L. Li, J. K. An, L. Zhao and N. Q. Ren, Bioresour. Technol., 2015, 178, 119-125. 